\title{
Insights into the role of connexins in mammary gland morphogenesis and function
}

\author{
Michael K G Stewart ${ }^{1}$, Jamie Simek $^{1}$ and Dale W Laird ${ }^{1,2}$ \\ Departments of ${ }^{1}$ Physiology and Pharmacology and ${ }^{2}$ Anatomy and Cell Biology, University of Western Ontario, \\ London, Ontario, Canada N6A 5C1
}

Correspondence should be addressed to D W Laird; Email: dale.laird@schulich.uwo.ca

\begin{abstract}
Gap junctions formed of connexin subunits link adjacent cells by direct intercellular communication that is essential for normal tissue homeostasis in the mammary gland. The mammary gland undergoes immense remodeling and requires exquisite regulation to control the proliferative, differentiating, and cell death mechanisms regulating gland development and function. The generation of novel genetically modified mice with reduced or ablated connexin function within the mammary gland has advanced our understanding of the role of gap junctions during the complex and dynamic process of mammary gland development. These studies have revealed an important stagespecific role for Cx26 (GJA1) and Cx43 (GJB2), while Cx30 (GJB6) and Cx32 (Gjb1) can be eliminated without compromising the gland. Yet, there remain gaps in our understanding of the role of mammary gland gap junctions.

Reproduction (2015) 149 R279-R290
\end{abstract}

\section{Introduction}

Gap junctions are formed when six connexins cooligomerize to form a connexon, or hemichannel, which docks with a connexon from an adjacent cell to form a gap junction channel (Laird 2006). Gap junction channels directly link the cytoplasm of adjacent cells allowing for the exchange of molecules $<1 \mathrm{kDa}$ in size that includes ions and second messengers $\left(\mathrm{Ca}^{2+}, \mathrm{IP}_{3}\right.$, CAMP) in a process known as gap junctional intercellular communication (GJIC) (Laird 2006). We now know that 21 connexins exist in humans, while 20 connexins are found in mouse, and generally multiple connexins are expressed within the same cell (Laird 2006). However, channels formed by one connexin cannot always compensate for the loss of channel function from another because various connexins possess distinct gating properties and conductance when forming homomeric connexons formed exclusively of one connexin isoform (Laird 2006, Harris 2007). In addition, some connexins, such as $C \times 26$ (Gjb2), $C \times 30$ (Gjb6), and Cx32 (Gjb1), are able to intermix and form heteromeric connexons composed of multiple connexin isoforms, which display altered permeability characteristics and gating sensitivities that likely reflect the biological need of the cell type in vivo (Harris 2007, Locke et al. 2007). In addition, apart from GJIC-dependent functions, connexins may also control cellular function independent of GIIC through the formation of gap junction hemichannels linking the intracellular and extracellular environment or through poorly understood regulatory protein-protein interactions (Goodenough \& Paul 2003, Laird 2010). Importantly, gap junctions are expressed in almost every cell type in the human body, including those of the breast, and are dynamically regulated throughout organ and tissue morphogenesis, suggesting a role in the regulation of developmental processes (Wei et al. 2004, Laird 2006). As the majority of its development occurs after birth, the breast remains a fascinating organ to study the role of connexins in development.

The human breast, similar to that of the mouse mammary gland, functions to provide both nutrition and passive immunological protection against pathogens during nursing. Both are composed of a bilayered epithelial network consisting of a single luminal layer surrounded by a layer of myoepithelial cells separated from the mammary stroma by a basement membrane (Richert et al. 2000, Geddes 2007). However, while the non-pregnant rodent mammary gland consists entirely of a single ductal tree consisting of blunt ended ducts that develop alveolar buds in response to the estrous cycle within a mainly adipose-rich mammary fat pad, the human mammary gland contains 15-20 independent branching epithelial networks that begin as terminal duct lobular units composed of alveoli and ducts surrounded by fibrous connective tissue (Sternlicht et al. 2006, Geddes 2007). Importantly, both human and mouse mammary glands undergo extensive proliferation and secretory differentiation of epithelium as the breast develops into a secretory gland during lactation, which 
require tight regulation of hormonal and growth factor cues as well as epithelial-epithelial and epithelialstromal interactions, and direct cell-cell communication through gap junctions (Hennighausen \& Robinson 2005, Geddes 2007, McLachlan et al. 2007, Macias \& Hinck 2012). Therefore, it is unsurprising that the human and mouse epithelial stem cell hierarchies share many parallels as reviewed by Visvader (2009). Ultimately, due to these similarities between the mouse and human mammary gland, the mouse mammary gland has become a useful model to further our understanding of the mechanisms associated with gland development and disease, particularly through our ability to genetically manipulate molecular functions by mutation or ablation (Howlin et al. 2006, Brisken 2013). The evaluation of genetically modified mice has extended our understanding of the role of connexins in the mammary gland, which is discussed in this review.

\section{Mouse mammary gland development}

The development of the murine mammary gland begins with the development of the milk lines at embryonic day 10 (Cowin \& Wysolmerski 2010). By embryonic day 11.5, the milk lines develop into five pairs of mammary gland placodes which progress into mammary gland buds and ultimately a rudimentary ductal structure (Macias \& Hinck 2012). Following birth, this rudimentary structure develops isometrically with body weight until the onset of puberty (Howlin et al. 2006). The hormonal secretion of estrogen and growth hormone $(\mathrm{GH})$ then drives the first main phase of development by orchestrating ductal elongation from proliferative structures known as terminal end buds that invade the surrounding stroma and bifurcate creating new primary branches. These branches together with secondary lateral side branching loosely fill the mammary gland fat pad (Macias \& Hinck 2012). The adult mammary gland continues to undergo additional tertiary branching in response to cyclical ovarian estrus cycles further developing a highly branched epithelial network with the development of alveolar-like structures that cyclically regress until the onset of pregnancy (Sternlicht et al. 2006).

The second phase of mammary gland development occurs following the onset of pregnancy and is characterized by massive amounts of cell proliferation and tissue remodeling (Hennighausen \& Robinson 2005). The gland undergoes extensive alveolar development to acquire a secretory lobuloalveolar phenotype (Oakes et al. 2006). During early pregnancy, prolactin and progesterone are the main drivers of extensive branching of ducts and alveolar bud formation that continues during late pregnancy and into lactation (Macias \& Hinck 2012). As a result, the volume ratio of epithelial cells to adipocytes increases as the epithelial compartment expands and adipocytes undergo delipidation (Anderson et al. 2007). In parallel to the morphogenic changes in the pregnant mammary gland, luminal epithelial cells undergo differentiation as many genes involved in milk synthesis begin to be expressed during midpregnancy (Anderson et al. 2007). With the withdrawal of progesterone at parturition, the gland undergoes secretory activation as the mammary gland is set up as an exocrine gland to perform its main function to produce, secrete, and deliver milk (Pang \& Hartmann 2007). The gland functions to produce milk until weaning of the pups where the buildup of milk within alveoli acts as a trigger for the mammary gland to undergo involution. This two-step process is characterized by extensive cell death and remodeling that returns the mammary gland back to the adult gland state (Watson \& Kreuzaler 2011). The first phase of involution is characterized by extensive cell death, triggered by the activation of the LIF/Stat3 pathway, while the second phase of involution is characterized by remodeling of the extracellular matrix, adipocyte differentiation, and alveolar collapse (Macias \& Hinck 2012).

\section{Expression of connexins in the rodent mammary gland}

Up until about 2004, the majority of studies evaluating connexins in the rodent mammary gland focused on characterizing connexin expression, localization, and regulation (Fig. 1). Gap junctions were first detected joining ductal epithelial cells in 3 to 9-week old mammary glands of mice (Pitelka et al. 1973). These likely represented gap junctions made from $C \times 43$ (Gja1) as the vast majority of studies agree that $C \times 43$ is expressed in the basal epithelium and stroma, and further represents the major connexin expressed in the non-pregnant rodent mammary gland (Pozzi et al. 1995, Locke et al. 2004, Talhouk et al. 2005, Lambe et al. 2006, Plante \& Laird 2008). Cx43 is also reported to be transcriptionally upregulated in 5 to 6 -week old virgin mice, suggesting a role in the development of pubertal mammary gland (Lambe et al. 2006). Other connexins expressed between luminal cells of the nonpregnant mammary gland are $C \times 26, C \times 32$, and $C \times 30$ (Talhouk et al. 2005, Plante \& Laird 2008). However, these connexins remain poorly characterized based on low connexin expression, poor sensitivity of anti-connexin antibodies, variations in tissue processing, and differences in mouse strains being investigated (Monaghan et al. 1994, Locke et al. 2000, 2004, Yamanaka et al. 2001).

Following the onset of pregnancy, the connexin expression landscape changes as $C \times 26$ and $C \times 30$ are upregulated and begin to become the dominant connexins expressed within the mammary gland during pregnancy, suggesting a role in the regulation of mammary gland alveologenesis and differentiation (Monaghan et al. 1994, Talhouk et al. 2005). In the case of $C \times 26$, the majority of studies support a modest upregulation by day 5 of pregnancy (Monaghan et al. 1994, Locke et al. 2004), 
a dramatic upregulation at day 9-10 of pregnancy (Locke et al. 2000, 2004, Talhouk et al. 2005), before peaking near parturition (Monaghan et al. 1994, Pozzi et al. 1995, Locke et al. 2000, 2004, Yamanaka et al. 2001, Stewart et al. 2014). Alternatively, Cx30 appears to increase between days 10.5 and 12.5 of pregnancy before peaking in late pregnancy before parturition (Talhouk et al. 2005, Locke et al. 2007). When Cx26 and Cx30 are coexpressed in mammary epithelium, they colocalize into the same gap junction plaque and form heteromeric channels in vitro (Locke et al. 2007). In contrast, Cx32 expression remains low throughout pregnancy before extensive upregulation following the onset of lactation, suggesting a role in regulation of the secretory phenotype of the gland as opposed to regulation of alveologenesis (Locke et al. 2000, Yamanaka et al. 2001, Talhouk et al. 2005). In myoepithelial cells, Cx43 protein expression undergoes a slight increase during pregnancy, associated with a shift to more highly phosphorylated forms of $\mathrm{Cx} 43$ which are commonly associated with greater GIIC (Yamanaka et al. 1997, El-Sabban et al. 2003, Talhouk et al. 2005). Changes in Cx43 correlate with the expression of MAP kinases ERK $1 / 2$ and JNK in primary rat mammary epithelial cells and may be indicative of more functionally active gap junctions, although this has not been demonstrated directly in vivo (Seo et al. 2006).

Following parturition, gap junctions between luminal epithelial cells lining alveoli become larger and less numerous than those during pregnancy (Pitelka et al. 1973) because elevated and intermixed luminal Cx26, Cx30, and Cx32 channels continue to be colocalized (Locke et al. 2000, 2007, Yamanaka et al. 2001). The different temporal onset of Cx26, Cx30, and Cx32 as the gland transitions from pregnancy through lactation promotes discrete heteromeric and homomeric gap junctions with distinct permeabilities of regulatory molecules $\mathrm{IP}_{3}$, CAMP, and cGMP, as well as differences in channel insensitivity to closure by the osmolyte taurine present during milk protein synthesis (Locke et al. 2004, 2007). The physiological importance of this remains chiefly unknown and understudied due largely to a lag in the development of assays to measure channel activity in vivo. Heteromeric channels consisting of Cx30 appear to become obsolete following day 7 of lactation because $\mathrm{Cx} 30$ levels decrease to a pre-pregnant state (Talhouk et al. 2005, Locke et al. 2007). Typical of exocrine glands, most studies agree that both Cx26 and Cx32 are reported to maintain elevated expression throughout lactation compared with the virgin gland, until the onset of involution (Locke et al. 2000, 2004, Yamanaka et al. 2001, Serre-Beinier et al. 2002, Talhouk et al. 2005). Myoepithelial cells on the other hand continue to readily express $\mathrm{Cx} 43$ in surrounding alveoli throughout lactation (Pitelka et al. 1973, Yamanaka et al. 1997). The majority of studies suggest that there is a lack of gap junctions between luminal and myoepithelial cells of alveoli as historically assessed by electron microscopy (Pitelka et al. 1973, Yamanaka et al. 1997). However, more recent evidence has suggested that Cx43 may be localized near myoepithelial-luminal cell contacts based on immunofluorescence, suggesting possible heterocellular interactions (Talhouk et al. 2005). However, as $\mathrm{Cx} 43$ has not readily been described to be expressed in luminal cells of mice, it remains difficult to interpret which connexin expressed in luminal cells would be able to dock with Cx43 in myoepithelial cells. Future electron microscopy studies may best answer whether gap junctions are present between the luminal and myoepithelial cells of alveoli.

Unlike lactation, our knowledge of the expression of connexins during involution is limited. During the first $48 \mathrm{~h}$ of involution, large gap junctions between luminal cells of alveoli, similar to those found in lactating mice, are present (Pitelka et al. 1973). These gap junctions likely represent Cx26 as Cx32 levels drop dramatically following the onset of involution (Locke et al. 2004). Cx43 appears also to be expressed and has been described to increase between 6 and $48 \mathrm{~h}$ in the involuting mammary gland following weaning of the pups (Lambe et al. 2006). However, both Cx43 and Cx26 return to the pre-pregnant state of expression following 1 week of gland involution (Monaghan et al. 1994, Pozzi et al. 1995, Talhouk et al. 2005).

\section{Expression of connexins in the human breast}

Unlike that of the rodent gland, knowledge of connexin expression in the human breast is currently restricted to the non-pregnant adult (Fig. 2; Wilgenbus et al. 1992, Pozzi et al. 1995, Monaghan et al. 1996, Jamieson et al. 1998, Laird et al. 1999, Teleki et al. 2014). Spatial and temporal connexin expression in human breast development remains understudied due to the difficulty in obtaining pubertal, pregnant, and lactating human samples. Similar to that of the rodent gland, Cx43 is readily detected in the nonpregnant breast, localizing mainly with the myoepithelial marker keratin 14 forming gap junctions between basal cells of both the major ducts and lobules (Wilgenbus et al. 1992, Pozzi et al. 1995, Monaghan et al. 1996, Jamieson et al. 1998, Laird et al. 1999, Teleki et al. 2014). In addition, sparse $\mathrm{Cx} 43$ gap junction plaques between luminal cells have been reported, raising the potential for Cx43 gap junctions between myoepithelial and luminal cells, although this is likely a rare event based on a lack of evidence for luminal-myoepithelial gap junctions at the ultrastructural level (Monaghan et al. 1996, Laird et al. 1999). In addition, Cx26 has been observed localized between luminal epithelial cells (Monaghan et al. 1996, Teleki et al. 2014). Cx26 expression is likely low and its expression may reflect dynamic hormonal variation due to monthly cycles or inter-patient variability as many studies have failed to detect Cx26 in ducts or lobules based on immunolabeling and electron 

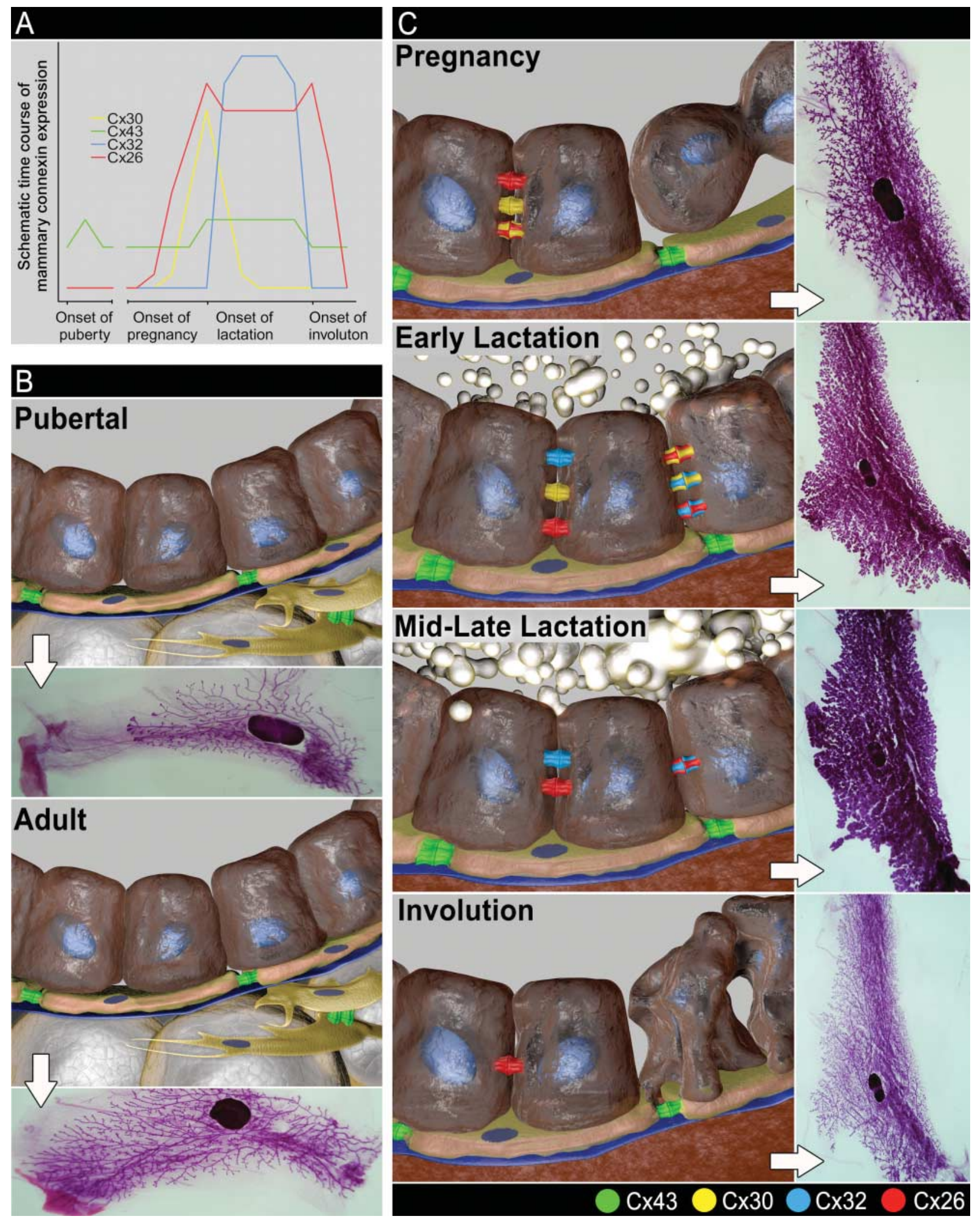
microscopy (Wilgenbus et al. 1992, Pozzi et al. 1995, Monaghan et al. 1996, Jamieson et al. 1998).

Until recently, no other connexin was reported in the human mammary gland. However, Teleki et al. (2014) have recently described both $\mathrm{C} \times 32$ and $\mathrm{C} \times 30$ in human breast luminal epithelial cells, similar to that found in the mammary glands of rodents, and Cx30 appeared to colocalize with Cx26. Cx30 was also described to be expressed within the microvasculature and myoepithelial cells, which in the latter case raises the possibility of heterocellular gap junctions between Cx26 and Cx30 expressed in luminal cells (Teleki et al. 2014). Intriguingly, these authors also identify Cx46 between luminal, myoepithelial, and inflammatory cells, despite a lack of expression in the rodent mammary gland, suggesting possible species-specific differences between human and rodent mammary glands (Locke et al. 2004, Teleki et al. 2014). Limitations of the Teleki study include low sample size and a lack of double immunolabeling with cell type-specific markers. However, while others have found only Cx43 and Cx26 in the human breast, the Teleki et al. study argues that a more rigorous re-evaluation of connexin expression at all stages of human breast development is needed. Importantly, these findings also suggest that connexin expression in the human breast may parallel more closely to that found in the mammary glands of rodents than previously thought.

\section{Role of connexins in mouse mammary gland development}

With the development of genetically modified mice expressing either loss-of-function connexin mutants or lacking a specific connexin (Table 1), the depth and understanding of connexins in the mammary gland has dramatically increased.

\section{Embryonic mammary development}

Mammary gland embryogenesis is mediated mostly by local mechanisms through epithelial-stromal interactions, suggesting a possible role for gap junctions in this process (Parmar \& Cunha 2004). To date, no study has evaluated connexin expression in prenatal mammary gland development, which is not surprising given that the majority of gland development occurs after birth (Levin 2002). However, a limited number of indirect studies suggest that connexins are not critical mediators of this process. The strongest argument for this stems from the fact that all Cx43, Cx26, Cx30, and Cx32 genetically modified mice where the connexin is ablated or mutated can proceed to develop at least some kind of a rudimentary mammary gland, while others appear to exhibit no gland defects at all (Table 1). An obvious explanation for this may be that the impairment or loss of one connexin is compensated by another during this stage of development. Alternatively, another connexin family member may be expressed, which is not typically expressed at a similar stage of development, although no evidence exists for either of these two possibilities. In fact, adult stem/progenitor cells isolated from human mammoplasty (Kao et al. 1995, Trosko \& Chang 2003) or from the bovine mammary gland (Holland et al. 2003) were found to lack GIIC, inferring that stem/progenitor cells in the mammary gland during embryogenesis may also lack GJIC. An in-depth screening of connexins during embryogenesis is necessary to determine if, and when, connexins are embryonically expressed in the developing gland.

\section{Virgin mammary gland}

Cx43 is the most highly expressed connexin in the virgin mammary gland, and is reported to be upregulated during puberty (Lambe et al. 2006). Hormonal control of ductal elongation at puberty is driven by estrogen and $\mathrm{GH}$ signaling, as estrogen receptor alpha null (ER $\alpha \mathrm{KO})$ and $\mathrm{GH}$ receptor null (GHRKO) mice both exhibit absent or impaired ductal elongation, respectively, without affecting rudimentary glnd growth before puberty (Gallego et al. 2001, Mueller et al. 2002). Although estrogen, $\mathrm{GH}$, as well as hormone insulin-like growth factor 1 has been implicated in the regulating the expression of $\mathrm{Cx} 43$ in other in vitro models, it still

Figure 1 Connexin expression throughout mouse mammary gland development. (A) Schematic rendering of Cx43 (green), Cx26 (red), Cx32 (blue), and Cx30 (yellow) expression throughout mammary gland development based on the body of evidence discussed in this review. (B) The first main phase of mammary gland development occurs through puberty as a rudimentary duct structure extends and branches throughout the fat pad. The virgin mammary gland epithelium contains luminal cells (brown) expressing low basal levels of Cx26, Cx30, and Cx32 (not shown) throughout virgin gland development. Luminal cells surrounded by myoepithelial cells (peach) connected by gap junctions composed of Cx43 (green) that are upregulated during puberty. The epithelium is embedded in the stroma that contains mainly adipocytes (clear), as well as fibroblasts (yellow) that express Cx43, separated by a basement membrane (dark blue). (C) The second main phase of development occurs following the onset of pregnancy as extensive lobuloalveolar development prepares the mammary gland to produce and deliver milk during lactation before the gland undergoes involution where extensive cell death and remodeling returns the gland to a pre-pregnant state. Cx26 and Cx30 are dramatically upregulated in luminal alveolar cells during pregnancy, while Cx32 is upregulated following parturition during early lactation. By mid lactation, Cx30 expression reverts back to the levels expressed in the virgin mammary gland, while Cx32 expression occurs at the onset of involution. Cx26 remains elevated throughout lactation and in the early stages of involution in luminal alveolar cells. In some instances, these connexins may selectively intermix to form heteromeric and heterotypic gap junction channels. Myoepithelial cells continue to express Cx43 gap junctions throughout pregnancy, lactation, and involution. Each developmental stage is paired with a representative epithelial architecture of the mice mammary gland as revealed by whole-mount analysis using carmine alum staining. 


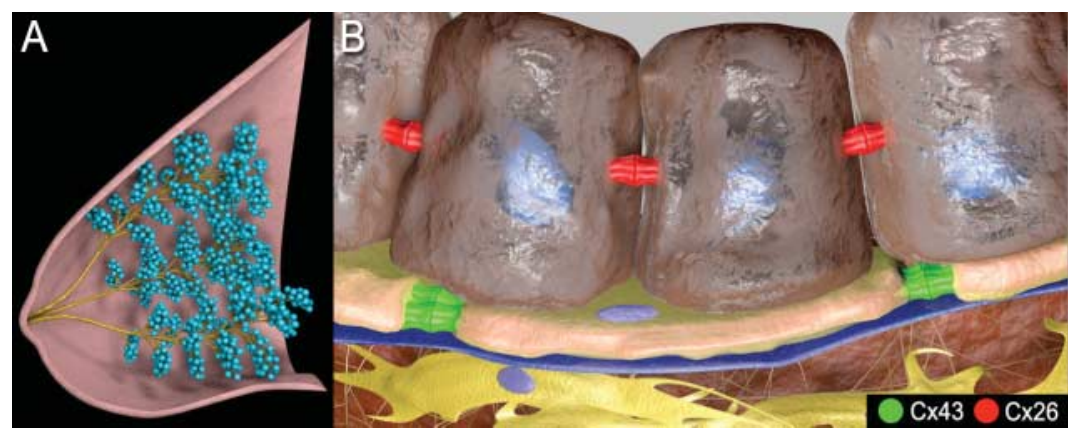

Figure 2 Connexin expression in the non-pregnant human breast. (A) Alveoli (blue) are connected to openings at the nipple by multiple converging duct systems (yellow). (B) The mammary epithelium consists of luminal cells (brown) connected by gap junctions composed of Cx26 (red), surrounded by myoepithelial cells (peach) connected by $\mathrm{C} \times 43$ (green) gap junctions. The epithelium is separated by a basement membrane (dark blue) from the connective tissue containing fibroblasts (yellow) linked by Cx43 gap junctions.

remains unclear whether these hormones regulate $\mathrm{C} x 43$ in the pubertal mammary gland (Aberg et al. 2000, 2003, Ren et al. 2013). Thus, it remains important to assess whether the levels of $\mathrm{Cx} 43$ change in ERaKO or GHRKO mice during puberty to identify upstream regulators of Cx43. Importantly, genetically modified mice where Cx43 is expressed but not fully functional have revealed impaired ductal phenotypes similar to ERaKO or GHRKO mice (Table 1).

One mutant mouse line that has proven to be insightful in our understanding of the mammary gland is $C \times 43^{\mathrm{G} 60 \mathrm{~S} /+}$ mutant mice. These mice mimic the human developmental disease known as oculodentodigital dysplasia
(ODDD). ODDD mice harbor a systemic autosomaldominant mutation in the gene that encodes $C \times 43$, which yields a glycine to serine substitution at position 60, rendering total Cx43 function to only $<30 \%$ of normal levels (Flenniken et al. 2005). Evaluation of 4 to 10-week virgin mutant mice revealed a severe delay in ductal elongation, as well as stromal impairment compared, with control mice in prepubertal, pubertal, and adult mice, highlighting a role for $\mathrm{Cx} 43$ in the regulation of epithelial morphogenesis and stromal development in the virgin gland (Plante \& Laird 2008). In addition, a second mutant mice model of ODDD that harbors a $C \times 43^{1130 T}$ mutant, yielding an isoleucine-to-threonine substitution at position

Table 1 Genetically modified mice used to evaluate the role of connexins in the mammary gland.

\begin{tabular}{|c|c|c|c|c|}
\hline Mouse line & $\begin{array}{l}\text { Background (DNA; ES cell; } \\
\text { Blastocyst; Cross) }\end{array}$ & Modification & Mammary gland phenotype & Reference \\
\hline $\mathrm{C} \times 43^{+/-}$ & 129 SV; 129 R1; C57BL/6 & Loss of one allele of $C \times 43$ & No defect reported & Reaume et al. (1995) \\
\hline $\mathrm{C} \times 43^{\mathrm{C} \times 40 /+}$ & 129 SV; HM1; C57BL/6; C57BL/6 & $\begin{array}{l}\text { Cx43 allele replaced with } \\
\text { Cx40 }\end{array}$ & $\begin{array}{l}\text { Normal development and } \\
\text { function }\end{array}$ & Plum et al. (2000) \\
\hline $\mathrm{C} \times 43^{\mathrm{C} \times 26 /+}$ & $\begin{array}{l}129 \mathrm{SV} ; \mathrm{HM} 1 ; \mathrm{C} 57 \mathrm{BL} / 6 ; \mathrm{C} 57 \mathrm{BL} / 6 \\
\text { and Flp }\end{array}$ & $\begin{array}{l}\text { Cx43 allele replaced with } \\
\text { Cx26 }\end{array}$ & $\begin{array}{l}\text { Reduced branching of } \\
\text { ductuli }\end{array}$ & $\begin{array}{l}\text { Winterhager et al. } \\
\text { (2007) }\end{array}$ \\
\hline $\mathrm{C} \times 43^{\mathrm{C} \times 32 /+}$ & $\begin{array}{l}129 \mathrm{SV} ; \mathrm{HM} 1 ; \mathrm{C} 57 \mathrm{BL} / 6 ; \mathrm{C} 57 \mathrm{BL} / 6 \\
\text { mammary transplant into } \\
\text { cleared fat pads of nude mice }\end{array}$ & $\begin{array}{l}\text { Cx43 allele replaced with } \\
\text { Cx32 }\end{array}$ & Normal gland development & Bry et al. (2004) \\
\hline $\mathrm{C} \times 43^{\mathrm{C} \times 32 /+}$ & 129 SV; HM1; C57BL/6; C57BL/6 & $\begin{array}{l}\text { Cx43 allele replaced with } \\
\text { Cx32 }\end{array}$ & Milk ejection defect & Plum et al. (2000) \\
\hline $\mathrm{C} \times 43^{1130 \mathrm{~T} /+}$ & $\begin{array}{l}129 \mathrm{R} 1 ; 129 \mathrm{R} 1 ; \mathrm{C} 57 \mathrm{BL} / 6 ; \mathrm{CD} 1 \\
\text { and C57BL/6 }\end{array}$ & $\begin{array}{l}\text { Point mutation in the Gja1 } \\
\text { gene causes I130T } \\
\text { substitution in one allele }\end{array}$ & $\begin{array}{l}\text { Virgin - delayed ductal } \\
\text { development in } \\
\text { pre-pubertal mice } \\
\text { Lactation - normal develop- } \\
\text { ment and function }\end{array}$ & Stewart et al. (2013) \\
\hline $\mathrm{C} \times 43^{\mathrm{G} 60 \mathrm{~S} /+}$ & $\begin{array}{l}\text { ENU mutagenized } \mathrm{C} 3 \mathrm{H} / \mathrm{He} \text {; } \\
\text { FVB; C3; C57BL/6 }\end{array}$ & $\begin{array}{l}\text { Point mutation in the Gja1 } \\
\text { gene causes G60S } \\
\text { substitution in one allele }\end{array}$ & $\begin{array}{l}\text { Virgin - delayed ductal and } \\
\text { stromal development } \\
\text { Lactation - milk stasis and } \\
\text { defect in milk ejection }\end{array}$ & $\begin{array}{l}\text { Plante \& Laird (2008) } \\
\text { and Plante et al. } \\
\text { (2010) }\end{array}$ \\
\hline $\mathrm{C} \times 32^{-1-}$ & $\begin{array}{l}\text { BALB/C; } 129 \text { SV J1; C57BL/6; } \\
\text { C57BL/6 }\end{array}$ & Loss of $C \times 32$ & Normal Gland Development & Bry et al. (2004) \\
\hline $\mathrm{C} \times 30^{-1-}$ & 129 SV; HM1; C57BL/6; C57BL/6 & Loss of $C \times 30$ & $\begin{array}{l}\text { Fertile, lactate; no rigorous } \\
\text { assessment reported }\end{array}$ & Teubner et al. (2003) \\
\hline $\mathrm{C} \times 26^{\mathrm{fl} / \mathrm{fl}} \times \mathrm{MMTV}$-Cre & $\begin{array}{l}\mathrm{C} \times 26^{\mathrm{fl} / \mathrm{fl}} \text { mice }-\mathrm{BALB} / \mathrm{C} ; \mathrm{HM} 1 ; \\
\text { C57BL/6; C57BL/6 } \\
\text { MMTV-Cre mice - not described }\end{array}$ & $\begin{array}{l}\text { Conditional deletion of } \mathrm{Cx} 26 \\
\text { prior to birth }\end{array}$ & $\begin{array}{l}\text { Virgin - normal development } \\
\text { Pregnancy - increased } \\
\text { apoptosis and decreased } \\
\text { alveologenesis }\end{array}$ & Bry et al. (2004) \\
\hline $\mathrm{C} \times 26^{\mathrm{fl} / \mathrm{fl}} \times$ WAP-Cre & $\begin{array}{l}\mathrm{C} \times 26^{\mathrm{fl} / \mathrm{fl}} \text { mice }-\mathrm{BALB} / \mathrm{c} ; \mathrm{HM} 1 ; \\
\mathrm{C} 57 \mathrm{BL} / 6 ; \mathrm{C} 57 \mathrm{BL} / 6 \\
\text { WAP-Cre mice }- \text { not described }\end{array}$ & $\begin{array}{l}\text { Conditional deletion of } C \times 26 \\
\sim \mathrm{D} 17 \text { of pregnancy }\end{array}$ & $\begin{array}{l}\text { Normal development and } \\
\text { function }\end{array}$ & Bry et al. (2004) \\
\hline $\mathrm{C} \times 26^{\mathrm{fl} / \mathrm{fl}} \times \mathrm{BLG}-\mathrm{Cre}$ & $\begin{array}{l}C \times 26^{f l / f I}-\mathrm{BALB} / \mathrm{C} ; \mathrm{HM} 1 ; \mathrm{C} 57 \mathrm{BL} / 6 ; \\
\text { C57BL/6 } \\
\text { BLG-Cre mice - CBA; C57BL/6 }\end{array}$ & $\begin{array}{l}\text { Conditional deletion of } \mathrm{Cx} 26 \\
\sim \mathrm{D} 12.5 \text { of pregnancy }\end{array}$ & $\begin{array}{l}\text { Normal development and } \\
\text { function }\end{array}$ & Stewart et al. (2014) \\
\hline
\end{tabular}


130, further elucidated our understanding of the role of Cx43 in puberty. $C \times 43^{1130 T /+}$ mice retain $50-60 \%$ normal Cx43 function and revealed similar ductal development following puberty as compared with control mice despite showing delayed ductal elongation in prepubertal mice. In addition, these mice maintained normal stromal development (Stewart et al. 2013). The combination of these $C x 43$ mutant mice studies highlight that a specific threshold of Cx43 is needed to maintain normal ductal morphogenesis that is correlated with GIIC. This is supported by the finding that virgin glands develop normally despite maintaining only one allele of $\mathrm{C}_{4} 43$ as observed in heterozygous $\mathrm{C} \times 43^{\mathrm{C} \times 32 /+}$ mice, in which one allele of $\mathrm{C} \times 43$ was replaced with that of $C \times 32$, as well as $C \times 43^{+/-}$mice, in which one allele for $\mathrm{Cx}_{4} 43$ has been removed (Reaume et al. 1995, Bry et al. 2004). However, as defects are observed in both, whether Cx43 is important in the epithelial and/or stromal compartments remains to be determined. Future studies where mutant $\mathrm{C} \times 43^{\mathrm{G} 60 \mathrm{~S} /+}$ mouse mammary epithelium is transplanted into WT mouse stroma and vice versa are needed to clarify the role that $C \times 43$ plays in ductal morphogenesis.

In the case of $\mathrm{Cx} 26$ and $\mathrm{Cx} 32$, which are normally expressed in mammary luminal cells, it is not surprising that mammary glands with conditionally ablated Cx26 and global Cx32-null mice exhibit normal virgin gland architecture as their expression is low in the non-pregnant mammary gland (Bry et al. 2004). Similarly, Cx30 appears dispensable in the virgin gland and also in the developing gland, as these mice are fertile and able to lactate, suggesting that a ductal network has been formed during adolescence, although a detailed evaluation of the virgin mammary gland in Cx30-null mice has not been performed (Teubner et al. 2003). Taken together, Cx43 appears to regulate ductal elongation and stromal development in the virgin mammary gland.

\section{Mammary gland during pregnancy}

Following the onset of pregnancy, Cx26 upregulation is likely driven by prolactin signaling because transcript profiling of mammary glands from prolactin receptor knockout mice (PrIRKO) revealed a downregulation of Cx26 compared with control mice during early pregnancy (Ormandy et al. 2003). In support of this, a binding site for STAT5, a downstream mediator of prolactin signaling, has been reported in the promoter of the Cx26 gene (Kiang et al. 1997). As Cx30 is also upregulated during pregnancy and colocalizes with Cx26, it is likely that it is also regulated by prolactin. Indeed, Talhouk et al. (2005) observed that exogenous administration of prolactin and the corticosteroid dexamethasone were able to upregulate Cx30 expression in mice mammary epithelial cells in vitro. Thus, both Cx26 and Cx30 appear to be regulated by the hormone prolactin.
Apart from prolactin signaling, Cx26 has also been shown to be upregulated by the administration of exogenous human chorionic gonadotropin (hCG) in rat mammary glands and ex vivo organ culture, through downstream activation of Sp transcription factors (Tu et al. 1998, You et al. 1998). However, as hCG treatment coincided with an increase in both $17 \beta$-estradiol and progesterone, it remains unclear how each hormone individually affects the levels of $\mathrm{Cx} 26$ or how the presence of multiple hormones alters the expression of Cx26 (You et al. 1998). Importantly, both estrogen and progesterone have been reported to regulate Cx26 expression in the endometrium of the uterus, suggesting that ovarian steroidal hormones may also regulate Cx26 in the mammary gland (Grummer et al. 1994). It remains unknown whether $\mathrm{Cx30}$ can also be hormonally regulated by hCG and ovarian steroids. Further studies are needed to understand hormonal regulation of $\mathrm{C} \times 26$ and $\mathrm{Cx} 30$, particularly in the more physiological context of multiple hormones.

Cx26 was first identified to be important in alveolar development during pregnancy following conditional deletion of $C \times 26$ before birth by crossing $C \times 26^{f l / f l}$ mice with mice expressing Cre under the mouse mammary tumor virus promoter (MMTV;Cx26 $6^{f / / f l}$ ) (Bry et al. 2004). These mice exhibited impaired alveologenesis and reduced the ability of the dams to feed their pups as a result of increased apoptosis (Bry et al. 2004). As such, the working model suggested that in response to prolactin and progesterone-driven alveologenesis, Cx26 is upregulated to promote epithelial cell survival within the pregnant mammary gland (Bry et al. 2004). However, two other conditionally ablated Cx26 mice models were created crossing $C \times 26^{f l / f l}$ mice with mice expressing Cre under the $\beta$-lactoglobulin (BLG;Cx26 fl/fl) or whey acidic acid (WAP) promoter (WAP; $C \times 26^{f / f l}$ ), yielding $C \times 26$ silencing during mid pregnancy or $C \times 26$ ablation during late pregnancy respectively. Unexpectedly, these mice revealed normal gland development and function, suggesting one of three possibilities (Bry et al. 2004, Stewart et al. 2014). Firstly, as low levels of Cx26 were observed in BLG;Cx26 fl/fl mice, a basal level of Cx26, and not the physiological surge, is sufficient to maintain normal mammary gland development. Secondly, Cx26 may be more important earlier in gland development than at day 12.5 when $C \times 26$ is ablated in BLG;Cx26 fl/fl mice. Based on the MMTV;CX26 $6^{f l / f l}$ and BLG;CX26 $6^{f l / f l}$ mutant mice, they predict the critical window for Cx26 in mammary gland development between $\sim 9.5$ and $\sim 12.5$ of pregnancy (Bry et al. 2004, Stewart et al. 2014). Finally, it remains to be seen whether the loss of $\mathrm{Cx} 26$ can be compensated by other connexins, such as $\mathrm{C} \times 30$. However, mutant mice studies thus far would suggest that this is not likely the case as conditional silencing of $C \times 26$ in mid pregnancy also delayed the upregulation of $C \times 30$ during pregnancy, suggesting that there is crosstalk between 
Cx26 and Cx30 (Stewart et al. 2014). A detailed evaluation of the mammary gland in $C \times 30^{-/-}$mice is lacking, but it would be interesting to evaluate changes in $C \times 26$ to determine whether there is a reciprocal crosstalk between $C \times 30$ and $C \times 26$ (Teubner et al. 2003). In addition, if $C \times 26$ and $C \times 30$ are coregulated, breeding of $C \times 30^{-1-}$ mice with mammary gland-ablated $C \times 26$ mice may yield a more severe mammary gland phenotype that would also address the issue of compensation.

Apart from extensive lobuloalveolar development that occurs in the mammary gland during pregnancy, the gland must also undergo differentiation as it prepares for secretory activation. To date, reduced or ablated $C \times 26$, $C \times 32, C \times 43$, or $C \times 30$ function suggests that loss of one connexin does not impair epithelial differentiation. For example in MMTV;Cx26 fl/ff -mutant mice, evaluation of numerous markers of epithelial differentiation including $\beta$-catenin, keratin 5, smooth muscle actin, E-cadherin, and the $\mathrm{NaKCl}$ cotransporter 1 suggested that the gland differentiated normally, despite reduced lobuloalveolar development, suggesting that $\mathrm{Cx} 26$ is not required to maintain normal epithelial differentiation (Bry et al. 2004). Similarly, loss of $C_{x} 43$ function in $C_{x} 43^{\mathrm{G} 60 \mathrm{~S} /+}$ mice was not associated with changes in the expression of E-cadherin, $\mathrm{P}$-cadherin, $\beta$-catenin, occludin, or claudin 1 molecules involved in tight and adherens junctions (Plante et al. 2010). In both these mice models, as well as in $C \times 32^{-/-}$and $C \times 30^{-1-}$-mutant mice, milk was produced, suggesting normal secretory differentiation of the gland and that no single connexin is essential for the production of milk, although a more rigorous assessment has not been performed (Teubner et al. 2003, Bry et al. 2004, Plante et al. 2010). Taken together, it is apparent that the loss of one connexin does not critically impede normal epithelial and secretory differentiation of the gland but the loss of $C \times 26$ does impair normal alveologenesis.

\section{Lactating mammary gland}

Following parturition, Cx32 is dramatically upregulated and appears to be under the control of prolactin signaling as both PrLrko and Stat5-null mice failed to express Cx32 during lactation (Miyoshi et al. 2001). Importantly, as both Cx26 and Cx30 are also suggested to be upregulated by prolactin but exhibit distinct temporal regulation compared with that of $\mathrm{C} \times 32$, additional hormonal or local mechanisms also likely influence the expression of Cx32. The expression of Cx32 and Cx26 during lactation is similar to that of all exocrine glands and is believed to function through the diffusion of ionic and molecular gradients allowing for coordinated secretion of adjacent cells in exocrine glands (Serre-Beinier et al. 2002). Despite this, both Cx32-null and mammary gland ablated Cx26-mice have revealed histological evidence of milk and lipid droplets in the lumen of alveoli, suggesting normal secretion of the gland (Bry et al. 2004, Stewart et al. 2014). However, the reduction in $\mathrm{Cx} 43$ function in the lactating gland of $\mathrm{C} \times 43^{\mathrm{G} 60 \mathrm{~S}} /+$ mice led to the presence of large cytoplasmic lipid droplets in luminal cells that have previously been implicated in delayed secretory activation (Anderson et al. 2007, Plante et al. 2010). As a result, only myoepithelial $\mathrm{C} \times 43$, and not luminal cell, that expressed Cx26 and Cx32 have been implicated in regulating the luminal secretory phenotype of the mammary gland albeit only when Cx43 function is greatly impaired.

Apart from the production and secretion of milk, the lactating mammary gland must coordinate the contraction of myoepithelial cells to propel milk from the alveoli through the converging duct system toward the nipple. Cx43 was first suggested to contribute to the coupling of myoepithelial cells during milk ejection based on a shift in the phosphorylation state of $\mathrm{Cx} 43$ in the myoepithelial cells during lactation (Yamanaka et al. 1997, Talhouk etal.2005). Although the hormonal control regulating the Cx43 phosphorylation shift and its increased expression are unknown. Likely candidates include estrogen and oxytocin because these have been shown to regulate the levels of $\mathrm{Cx} 43$ in the uterus and mice embryonic stem cells respectively (Risek et al. 1995, Yun et al. 2012).

Evidence of a role for $\mathrm{Cx} 43$ in milk ejection in vivo was not obtained until the assessment of knockin $C x 43$ mouse models in which one allele of $C \times 43$ was replaced by $C \times 32\left(C \times 43^{\mathrm{C} \times 32 /+}\right), C \times 26\left(C \times 43^{\mathrm{C} \times 26 /+}\right)$, or $C \times 40$ $\left(C \times 43^{\mathrm{C} \times 40 /+}\right)$. For example, mammary glands of lactating $C \times 43^{\mathrm{C} \times 32 /+}$ and $C \times 43^{\mathrm{C} \times 26 /+}$ were unable to feed their pups despite evidence of milk production and secretion (Plum et al. 2000, Winterhager et al. 2007). Surprisingly, $\mathrm{C} \times 43^{+/-}$mice have no reported defect in mammary gland development or function, thus it may be the additional expression of $\mathrm{C} \times 26$ and $\mathrm{C} \times 32$ in myoepithelial cells, rather than the $50 \%$ loss of function of $C \times 43$, which is ultimately responsible for the gland defects (Reaume et al. 1995). Although not directly demonstrated, myoepithelial cells engineered to express Cx26 and $\mathrm{C} \times 32$ could allow for gap junctions between luminal and myoepithelial cells creating a gap junction channelmediated exchange that does not normally exist (White \& Bruzzone 2000). Conversely, when Cx43 is replaced with $\mathrm{C} \times 40$ in $\mathrm{C} \times 43^{\mathrm{C} \times 40 /+}$ mice, there is no luminal/ myoepithelial exchange possibility because $\mathrm{Cx} 40$ in the myoepithelial cells is unable to form heterotypic channels with the $\mathrm{C} \times 26, \mathrm{C} \times 30$, or $\mathrm{C} \times 32$ found in luminal cells, and these mice continue to lactate and feed their pups (Plum et al. 2000).

The critical role for $\mathrm{Cx} 43$ in milk ejection was established later as the reduction in $\mathrm{Cx} 43$ by $70 \%$ in $C \times 43^{\mathrm{G} 60 \mathrm{~S} /+}$ mice led to a defect in the ability of the mammary gland to respond to oxytocin despite normal expression of the oxytocin receptor (Plante \& Laird 2008). Thus, it was concluded that Cx43 functions to coordinate 
synchronous contractions of myoepithelial cells for proper milk ejection (Plante \& Laird 2008). This was corroborated by others where WNT5A overexpression in human MCF10A cells led to an increase in Cx43 phosphorylation at serine P368 and a decrease in GJIC, suggesting that WNT5A negatively regulates $\mathrm{Cx} 43$ function (Baxley et al. 2011). Indeed, WNT5a overexpression in the mammary glands of lactating mice resulted in a similar inability of these mice to respond to exogenous oxytocin, further supporting a critical role of Cx43 in coordinating timely and proper milk ejection (Baxley et al. 2011). Oxytocin signaling is mediated through the oxytocin receptor coupled to $G_{\alpha q} 11$ and phospholipase $\mathrm{C}$ activation, triggering the release of $\mathrm{Ca}^{2+}$ from intracellular stores (Reversi et al. 2005). $\mathrm{Ca}^{2+}$ has previously been shown to pass through $\mathrm{Cx} 43$ gap junctions, making it interesting to speculate that Cx43 functions via GJIC-dependent mechanisms to coordinate synchronous contraction via transfer of $\mathrm{Ca}^{2+}$ (Harris 2007). This is supported by the fact that $C \times 43^{1130 \mathrm{~T} /+}$ mice with $\sim 50 \%$ Cx43 function retain full myoepithelial function (Stewart et al. 2013). In summary, the evidence to date points to a critical GJIC-dependent role for Cx43 in coordinating myoepithelial contraction and milk ejection; however, a milk ejection defect is only present when $\mathrm{Cx} 43$ function is found to be well below $50 \%$.

\section{Involuting mammary gland}

Only Cx26 and Cx43 are described as being expressed during the first 48-h involution. To date, no evidence exists that would suggest connexins are critical for the mammary gland to undergo involution. Both genetically modified mice with either a Cx26-knockdown mammary gland or expressing the loss-of-function $C \times 43^{1130}$ mutant have revealed similar epithelial remodeling and cell death during involution compared with control mice (Stewart et al. 2013, 2014). In addition, Cx26-ablated mammary gland did not initiate precocious involution of the gland despite an increase in the number of apoptotic cells during pregnancy because STAT3 phosphorylation, a marker and critical regulator of involution, did not increase (Bry et al. 2004). On the basis of limited evidence to date, connexins appear not to be drivers in the initiation or progression of epithelial cell death during mammary gland involution, but instead act like passengers that are altered following transition from the lactation phase of mammary gland development.

\section{Concluding remarks}

Our assessment of gap junctions in the mammary gland using genetically modified mice has established a role for Cx43 in ductal elongation during puberty, Cx26 in alveologenesis during pregnancy, and $\mathrm{Cx} 43$ in milk ejection during lactation. Future studies may use these tools to further expand our understanding of connexins in the mammary gland. Firstly, knock-in strategies using the $L a c Z$ reporter gene may be useful to support previous connexin expression studies as was used to assess the expression of $\mathrm{C} \times 30$ in the heart and $\mathrm{C} \times 26$ in the brain (Filippov et al. 2003, Gros et al. 2010). Secondly, Cx43mutant mice models or conditional knockout mouse models of Cx26 may be used to more closely evaluate specific features of development, which are not possible in vitro. These could include a closer examination of the possible role for $\mathrm{Cx} 43$ in terminal end-bud growth during the pubertal stage of development or more rigorous assessment of involution using multiple time points respectively. In addition, to provide further insights into the cell-specific function of $\mathrm{Cx} 43$, the role of $\mathrm{Cx} 43$ in myoepithelial cells may be evaluated using conditional deletion under the K14 promoter. Alternatively, to better assess how loss of connexins affects mammary gland function, a quantitative evaluation of milk components following the milking of mice with reduced connexin function may be useful to reveal more subtle changes in milk secretion (DePeters \& Hovey 2009). Perhaps most importantly, the cross-breeding strategy of Cx30 and Cx32-knockout mice with Dox-inducible conditional knockout of $C \times 26$ may be best to tackle issues of compensation and establish a clear role for luminal connexins in the mammary gland during pregnancy (Gunther et al. 2002). Although the details by which gap junctions regulate the development or function of the gland remains unclear, genetically modified mice have provided the tools to more rigorously assess previous predictions based on temporal connexin expression patterns in vivo and in vitro studies.

Importantly, it has become clear that our understanding of connexins in the mouse mammary gland may have implications extending to a wider appreciation of connexins in human health. For example, mutations in the genes encoding $C \times 43$ and $C \times 26$ give rise to ODDD and hearing loss respectively (Apps et al. 2007, Paznekas et al. 2009). In the case of Cx43, the rarity of ODDD in the human population and scarcity of clinical records make it difficult to assess whether these patients have breast function or development abnormalities (Paznekas et al. 2009). Nevertheless, our mutant mouse model studies suggest that distinct populations of ODDD patients may present with breast feeding problems that is dependent on the severity of the Cx43 mutant on overall Cx43-based GIIC (Plante \& Laird 2008, Stewart et al. 2013). However, unlike ODDD, deafness linked to Cx26 mutations is incredibly prevalent in the human population. In fact, it has been estimated that $17.3 \%$ of worldwide hearing loss is associated with biallelic mutations in the gene that encodes Cx26 (Chan \& Chang 2014). On the basis of mice studies where loss of Cx26 function impaired normal lobuloalveolar development of the gland, these patients may represent a yet unidentified population with increased risk of 
developing breast feeding defects (Bry et al. 2004). However, as yet, there are no epidemiology studies to determine whether female patients harboring a subclass of loss-of-function or gain-of-function Cx26 mutants have any breast defects as the data set is difficult to ascertain. In addition, both $C \times 43$ and $C \times 26$ are implicated in other breast-related diseases such as cancer, which has previously been reviewed by El-Saghir et al. (2011), although it remains unclear whether patients with loss-of-function mutations in the genes that encode $C x 43$ or $C x 26$ are predisposed (Naus \& Laird 2010). Ultimately, our understanding of the role of gap junction proteins in normal breast physiology will provide future insights into the pathologies of the breast and the possible development of targeted therapeutics.

\section{Declaration of interest}

The authors declare that there is no conflict of interest that could be perceived as prejudicing the impartiality of the review.

\section{Funding}

This review was supported in part by funding from the Canadian Breast Cancer Foundation and Canada Research Chair program to D W Laird. M K G Stewart was supported by the Canadian Institutes of Health Research Strategic Training Program in Cancer Research and Technology Transfer and a Translational Breast Cancer Studentship award funded in part by the Breast Cancer Society of Canada.

\section{References}

Aberg ND, Carlsson B, Rosengren L, Oscarsson J, Isaksson OG, Ronnback L \& Eriksson PS 2000 Growth hormone increases connexin-43 expression in the cerebral cortex and hypothalamus. Endocrinology 141 3879-3886.

Aberg ND, Blomstrand F, Aberg MA, Bjorklund U, Carlsson B, CarlssonSkwirut C, Bang P, Ronnback L \& Eriksson PS 2003 Insulin-like growth factor-I increases astrocyte intercellular gap junctional communication and connexin43 expression in vitro. Journal of Neuroscience Research 74 12-22. (doi:10.1002/jnr.10734)

Anderson SM, Rudolph MC, McManaman JL \& Neville MC 2007 Key stages in mammary gland development. Secretory activation in the mammary gland: it's not just about milk protein synthesis!. Breast Cancer Research 9 204. (doi:10.1186/bcr1653)

Apps SA, Rankin WA \& Kurmis AP 2007 Connexin 26 mutations in autosomal recessive deafness disorders: a review. International Journal of Audiology 46 75-81. (doi:10.1080/14992020600582190)

Baxley SE, Jiang W \& Serra R 2011 Misexpression of wingless-related MMTV integration site $5 \mathrm{~A}$ in mouse mammary gland inhibits the milk ejection response and regulates connexin43 phosphorylation. Biology of Reproduction 85 907-915. (doi:10.1095/biolreprod.111.091645)

Brisken C 2013 Progesterone signalling in breast cancer: a neglected hormone coming into the limelight. Nature Reviews. Cancer 13 385-396. (doi:10.1038/nrc3518)

Bry C, Maass K, Miyoshi K, Willecke K, Ott T, Robinson GW \& Hennighausen L 2004 Loss of connexin 26 in mammary epithelium during early but not during late pregnancy results in unscheduled apoptosis and impaired development. Developmental Biology 267 418-429. (doi:10.1016/j.ydbio.2003.11.022)
Chan DK \& Chang KW 2014 GJB2-associated hearing loss: systematic review of worldwide prevalence, genotype, and auditory phenotype. Laryngoscope 124 E34-E53. (doi:10.1002/lary.24332)

Cowin P \& Wysolmerski J 2010 Molecular mechanisms guiding embryonic mammary gland development. Cold Spring Harbor Perspectives in Biology 2 a003251. (doi:10.1101/cshperspect.a003251)

DePeters EJ \& Hovey RC 2009 Methods for collecting milk from mice. Journal of Mammary Gland Biology and Neoplasia 14 397-400. (doi:10. 1007/s10911-009-9158-0)

El-Sabban ME, Abi-Mosleh LF \& Talhouk RS 2003 Developmental regulation of gap junctions and their role in mammary epithelial cell differentiation. Journal of Mammary Gland Biology and Neoplasia 8 463-473. (doi:10.1023/B:JOMG.0000017432.04930.76)

El-Saghir JA, El-Habre ET, El-Sabban ME \& Talhouk RS 2011 Connexins: a junctional crossroad to breast cancer. International Journal of Developmental Biology 55 773-780. (doi:10.1387/ijdb.113372je)

Filippov MA, Hormuzdi SG, Fuchs EC \& Monyer H 2003 A reporter allele for investigating connexin 26 gene expression in the mouse brain. European Journal of Neuroscience 18 3183-3192. (doi:10.1111/j.14609568.2003.03042.x)

Flenniken AM, Osborne LR, Anderson N, Ciliberti N, Fleming C, Gittens JE, Gong XQ, Kelsey LB, Lounsbury C, Moreno L et al. 2005 A Gja1 missense mutation in a mouse model of oculodentodigital dysplasia. Development 132 4375-4386. (doi:10.1242/dev.02011)

Gallego MI, Binart N, Robinson GW, Okagaki R, Coschigano KT, Perry J, Kopchick JJ, Oka T, Kelly PA \& Hennighausen L 2001 Prolactin, growth hormone, and epidermal growth factor activate Stat5 in different compartments of mammary tissue and exert different and overlapping developmental effects. Developmental Biology 229 163-175. (doi:10. 1006/dbio.2000.9961)

Geddes DT 2007 Inside the lactating breast: the latest anatomy research. Journal of Midwifery \& Women's Health 52 556-563. (doi:10.1016/ j.jmwh.2007.05.004)

Goodenough DA \& Paul DL 2003 Beyond the gap: functions of unpaired connexon channels. Nature Reviews. Molecular Cell Biology 4 285-294. (doi:10.1038/nrm1072)

Gros D, Theveniau-Ruissy M, Bernard M, Calmels T, Kober F, Sohl G, Willecke K, Nargeot J, Jongsma HJ \& Mangoni ME 2010 Connexin 30 is expressed in the mouse sino-atrial node and modulates heart rate. Cardiovascular Research 85 45-55. (doi:10.1093/cvr/cvp280)

Grummer R, Chwalisz K, Mulholland J, Traub O \& Winterhager E 1994 Regulation of connexin26 and connexin 43 expression in rat endometrium by ovarian steroid hormones. Biology of Reproduction $\mathbf{5 1}$ 1109-1116. (doi:10.1095/biolreprod51.6.1109)

Gunther EJ, Belka GK, Wertheim GB, Wang J, Boxer RB \& Chodosh LA 2002 A novel doxycycline-inducible system for the transgenic analysis of mammary gland biology. FASEB Journal 16 283-292. (doi:10.1096/fj.01-0551com)

Harris AL 2007 Connexin channel permeability to cytoplasmic molecules. Progress in Biophysics and Molecular Biology 94 120-143. (doi:10. 1016/j.pbiomolbio.2007.03.011)

Hennighausen L \& Robinson GW 2005 Information networks in the mammary gland. Nature Reviews. Molecular Cell Biology 6 715-725. (doi:10.1038/nrm1714)

Holland MS, Tai MH, Trosko JE, Griffin LD, Stasko JA, Cheville NC \& Holland RE 2003 Isolation and differentiation of bovine mammary gland progenitor cell populations. American Journal of Veterinary Research 64 396-403. (doi:10.2460/ajvr.2003.64.396)

Howlin J, McBryan J \& Martin F 2006 Pubertal mammary gland development: insights from mouse models. Journal of Mammary Gland Biology and Neoplasia 11 283-297. (doi:10.1007/s10911-006-9024-2)

Jamieson S, Going JJ, D'Arcy R \& George WD 1998 Expression of gap junction proteins connexin 26 and connexin 43 in normal human breast and in breast tumours. Journal of Pathology 184 37-43. (doi:10.1002/ (SICI)1096-9896(199801)184:1 <37::AID-PATH966 > 3.0.CO;2-D)

Kao CY, Nomata K, Oakley CS, Welsch CW \& Chang CC 1995 Two types of normal human breast epithelial cells derived from reduction mammoplasty: phenotypic characterization and response to SV40 transfection. Carcinogenesis 16 531-538. (doi:10.1093/carcin/16.3.531)

Kiang DT, Jin N, Tu ZJ \& Lin HH 1997 Upstream genomic sequence of the human connexin26 gene. Gene 199 165-171. (doi:10.1016/S03781119(97)00365-X) 
Laird DW 2006 Life cycle of connexins in health and disease. Biochemical Journal 394 527-543. (doi:10.1042/BJ20051922)

Laird DW 2010 The gap junction proteome and its relationship to disease. Trends in Cell Biology 20 92-101. (doi:10.1016/j.tcb.2009.11.001)

Laird DW, Fistouris P, Batist G, Alpert L, Huynh HT, Carystinos GD \& Alaoui-Jamali MA 1999 Deficiency of connexin43 gap junctions is an independent marker for breast tumors. Cancer Research 59 4104-4110.

Lambe T, Finlay D, Murphy M \& Martin F 2006 Differential expression of connexin 43 in mouse mammary cells. Cell Biology International $\mathbf{3 0}$ 472-479. (doi:10.1016/j.cellbi.2006.02.008)

Levin M 2002 Isolation and community: a review of the role of gap-junctional communication in embryonic patterning. Journal of Membrane Biology 185 177-192. (doi:10.1007/s00232-001-0129-7)

Locke D, Perusinghe N, Newman T, Jayatilake H, Evans WH \& Monaghan P 2000 Developmental expression and assembly of connexins into homomeric and heteromeric gap junction hemichannels in the mouse mammary gland. Journal of Cellular Physiology 183 228-237. (doi:10. 1002/(SICl) 1097-4652(200005)183:2 <228::AID-JCP9 > 3.0.CO;2-Y)

Locke D, Stein T, Davies C, Morris J, Harris AL, Evans WH, Monaghan P \& Gusterson B 2004 Altered permeability and modulatory character of connexin channels during mammary gland development. Experimental Cell Research 298 643-660. (doi:10.1016/j.yexcr.2004.05.003)

Locke D, Jamieson S, Stein T, Liu J, Hodgins MB, Harris AL \& Gusterson B 2007 Nature of Cx30-containing channels in the adult mouse mammary gland. Cell and Tissue Research 328 97-107. (doi:10.1007/s00441-006-0301-6)

Macias H \& Hinck L 2012 Mammary gland development. Wiley Interdisciplinary Reviews. Developmental Biology1 533-557. (doi:10.1002/wdev.35)

McLachlan E, Shao Q \& Laird DW 2007 Connexins and gap junctions in mammary gland development and breast cancer progression. Journal of Membrane Biology 218 107-121. (doi:10.1007/s00232-007-9052-x)

Miyoshi K, Shillingford JM, Smith GH, Grimm SL, Wagner KU, Oka T, Rosen JM, Robinson GW \& Hennighausen L 2001 Signal transducer and activator of transcription (Stat) 5 controls the proliferation and differentiation of mammary alveolar epithelium. Journal of Cell Biology 155 531-542. (doi:10.1083/jcb.200107065)

Monaghan P, Perusinghe N, Carlile G \& Evans WH 1994 Rapid modulation of gap junction expression in mouse mammary gland during pregnancy, lactation, and involution. Journal of Histochemistry and Cytochemistry 42 931-938. (doi:10.1177/42.7.8014476)

Monaghan P, Clarke C, Perusinghe NP, Moss DW, Chen XY \& Evans WH 1996 Gap junction distribution and connexin expression in human breast. Experimental Cell Research 223 29-38. (doi:10.1006/excr.1996.0055)

Mueller SO, Clark JA, Myers PH \& Korach KS 2002 Mammary gland development in adult mice requires epithelial and stromal estrogen receptor $\alpha$. Endocrinology 143 2357-2365.

Naus CC \& Laird DW 2010 Implications and challenges of connexin connections to cancer. Nature Reviews. Cancer 10 435-441. (doi:10. 1038/nrc2841)

Oakes SR, Hilton HN \& Ormandy CJ 2006 The alveolar switch: coordinating the proliferative cues and cell fate decisions that drive the formation of lobuloalveoli from ductal epithelium. Breast Cancer Research 8 207. (doi:10.1186/bcr1411)

Ormandy CJ, Naylor M, Harris J, Robertson F, Horseman ND, Lindeman GJ, Visvader J \& Kelly PA 2003 Investigation of the transcriptional changes underlying functional defects in the mammary glands of prolactin receptor knockout mice. Recent Progress in Hormone Research 58 297-323. (doi:10.1210/rp.58.1.297)

Pang WW \& Hartmann PE 2007 Initiation of human lactation: secretory differentiation and secretory activation. Journal of Mammary Gland Biology and Neoplasia 12 211-221. (doi:10.1007/s10911-007-9054-4)

Parmar H \& Cunha GR 2004 Epithelial-stromal interactions in the mouse and human mammary gland in vivo. Endocrine-Related Cancer 11 437-458. (doi:10.1677/erc.1.00659)

Paznekas WA, Karczeski B, Vermeer S, Lowry RB, Delatycki M, Laurence F, Koivisto PA, Van Maldergem L, Boyadjiev SA, Bodurtha JN et al. 2009 GJA1 mutations, variants, and connexin 43 dysfunction as it relates to the oculodentodigital dysplasia phenotype. Human Mutation 30 724-733. (doi:10.1002/humu.20958)

Pitelka DR, Hamamoto ST, Duafala JG \& Nemanic MK 1973 Cell contacts in the mouse mammary gland. I. Normal gland in postnatal development and the secretory cycle. Journal of Cell Biology 56 797-818. (doi:10.1083/jcb.56.3.797)
Plante I \& Laird DW 2008 Decreased levels of connexin43 result in impaired development of the mammary gland in a mouse model of oculodentodigital dysplasia. Developmental Biology 318 312-322. (doi:10.1016/j.ydbio.2008.03.033)

Plante I, Wallis A, Shao Q \& Laird DW 2010 Milk secretion and ejection are impaired in the mammary gland of mice harboring a Cx43 mutant while expression and localization of tight and adherens junction proteins remain unchanged. Biology of Reproduction 82 837-847. (doi:10.1095/ biolreprod.109.081406)

Plum A, Hallas G, Magin T, Dombrowski F, Hagendorff A, Schumacher B, Wolpert C, Kim J, Lamers WH, Evert M et al. 2000 Unique and shared functions of different connexins in mice. Current Biology 10 1083-1091. (doi:10.1016/S0960-9822(00)00690-4)

Pozzi A, Risek B, Kiang DT, Gilula NB \& Kumar NM 1995 Analysis of multiple gap junction gene products in the rodent and human mammary gland. Experimental Cell Research 220 212-219. (doi:10.1006/excr. 1995.1308)

Reaume AG, de Sousa PA, Kulkarni S, Langille BL, Zhu D, Davies TC, Juneja SC, Kidder GM \& Rossant J 1995 Cardiac malformation in neonatal mice lacking connexin43. Science 267 1831-1834. (doi:10.1126/science.7892609)

Ren J, Wang XH, Wang GC \& Wu JH $201317 \beta$ estradiol regulation of connexin 43-based gap junction and mechanosensitivity through classical estrogen receptor pathway in osteocyte-like MLO-Y4 cells. Bone 53 587-596. (doi:10.1016/j.bone.2012.12.004)

Reversi A, Cassoni P \& Chini B 2005 Oxytocin receptor signaling in myoepithelial and cancer cells. Journal of Mammary Gland Biology and Neoplasia 10 221-229. (doi:10.1007/s10911-005-9583-7)

Richert MM, Schwertfeger KL, Ryder JW \& Anderson SM 2000 An atlas of mouse mammary gland development. Journal of Mammary Gland Biology and Neoplasia 5 227-241. (doi:10.1023/A:1026499523505)

Risek B, Klier FG, Phillips A, Hahn DW \& Gilula NB 1995 Gap junction regulation in the uterus and ovaries of immature rats by estrogen and progesterone. Journal of Cell Science 108 1017-1032.

Seo MS, Park JS, Yang SR, Park KS, Hong IS, Jo EH, Kang KS \& Lee YS 2006 Expression of MAP kinases and connexins in the differentiation of rat mammary epithelial cells. Journal of Veterinary Medical Science/the Japanese Society of Veterinary Science 68 567-571. (doi:10.1292/jvms. 68.567)

Serre-Beinier V, Mas C, Calabrese A, Caton D, Bauquis J, Caille D, Charollais A, Cirulli V \& Meda P 2002 Connexins and secretion. Biology of the Cell/Under the Auspices of the European Cell Biology Organization 94 477-492. (doi:10.1016/S0248-4900(02)00024-2)

Sternlicht MD, Kouros-Mehr H, Lu P \& Werb Z 2006 Hormonal and local control of mammary branching morphogenesis. Differentiation; Research in Biological Diversity 74 365-381. (doi:10.1111/j.1432-0436. 2006.00105.x)

Stewart MK, Gong XQ, Barr KJ, Bai D, Fishman GI \& Laird DW 2013 The severity of mammary gland developmental defects is linked to the overall functional status of $\mathrm{C} \times 43$ as revealed by genetically modified mice. Biochemical Journal 449 401-413. (doi:10.1042/BJ20121070)

Stewart MK, Plante I, Bechberger JF, Naus CC \& Laird DW 2014 Mammary gland specific knockdown of the physiological surge in Cx26 during lactation retains normal mammary gland development and function. PLOS ONE 9 e101546. (doi:10.1371/journal.pone.0101546)

Talhouk RS, Elble RC, Bassam R, Daher M, Sfeir A, Mosleh LA, El-Khoury H, Hamoui S, Pauli BU \& El-Sabban ME 2005 Developmental expression patterns and regulation of connexins in the mouse mammary gland: expression of connexin30 in lactogenesis. Cell and Tissue Research 319 49-59. (doi:10.1007/s00441-004-0915-5)

Teleki I, Szasz AM, Maros ME, Gyorffy B, Kulka J, Meggyeshazi N, Kiszner G, Balla P, Samu A \& Krenacs T 2014 Correlations of differentially expressed gap junction connexins cx26, cx30, cx32, cx43 and cx46 with breast cancer progression and prognosis. PLOS ONE 9 e112541. (doi:10.1371/journal.pone.0112541)

Teubner B, Michel V, Pesch J, Lautermann J, Cohen-Salmon M, Sohl G, Jahnke K, Winterhager E, Herberhold C, Hardelin JP et al. 2003 Connexin30 (Gjb6)-deficiency causes severe hearing impairment and lack of endocochlear potential. Human Molecular Genetics 12 13-21. (doi:10.1093/hmg/ddg001) 
Trosko JE \& Chang CC 2003 Isolation and characterization of normal adult human epithelial pluripotent stem cells. Oncology Research 13 353-357.

Tu ZJ, Kollander R \& Kiang DT 1998 Differential up-regulation of gap junction connexin 26 gene in mammary and uterine tissues: the role of Sp transcription factors. Molecular Endocrinology 12 1931-1938. (doi:10.1210/mend.12.12.0208)

Visvader JE 2009 Keeping abreast of the mammary epithelial hierarchy and breast tumorigenesis. Genes and Development 23 2563-2577. (doi:10.1101/gad.1849509)

Watson CJ \& Kreuzaler PA 2011 Remodeling mechanisms of the mammary gland during involution. International Journal of Developmental Biology 55 757-762. (doi:10.1387/ijdb.113414cw)

Wei CJ, Xu X \& Lo CW 2004 Connexins and cell signaling in development and disease. Annual Review of Cell and Developmental Biology 20 811-838. (doi:10.1146/annurev.cellbio.19.111301.144309)

White TW \& Bruzzone R 2000 Gap junctions: fates worse than death? Current Biology 10 R685-R688. (doi:10.1016/S0960-9822(00)00689-8)

Wilgenbus KK, Kirkpatrick CJ, Knuechel R, Willecke K \& Traub O 1992 Expression of $\mathrm{Cx} 26, \mathrm{C} \times 32$ and $\mathrm{C} \times 43$ gap junction proteins in normal and neoplastic human tissues. International Journal of Cancer. Journal International du Cancer 51 522-529. (doi:10.1002/ijc.2910510404)

Winterhager E, Pielensticker N, Freyer J, Ghanem A, Schrickel JW, Kim JS, Behr R, Grummer R, Maass K, Urschel S et al. 2007 Replacement of connexin 43 by connexin 26 in transgenic mice leads to dysfunctional reproductive organs and slowed ventricular conduction in the heart. BMC Developmental Biology 7 26. (doi:10.1186/1471-213X-7-26)

Yamanaka I, Kuraoka A, Inai T, Ishibashi T \& Shibata Y 1997 Changes in the phosphorylation states of connexin 43 in myoepithelial cells of lactating rat mammary glands. European Journal of Cell Biology 72 166-173.

Yamanaka I, Kuraoka A, Inai T, Ishibashi T \& Shibata Y 2001 Differential expression of major gap junction proteins, connexins 26 and 32, in rat mammary glands during pregnancy and lactation. Histochemistry and Cell Biology 115 277-284.

You S, Tu ZJ \& Kiang DT 1998 Direct modulation of tumor suppressor connexin 26 gene by human chorionic gonadotropin in rat mammary glands. Cancer Research 58 1498-1502.

Yun SP, Park SS, Ryu JM, Park JH, Kim MO, Lee JH \& Han HJ 2012 Mechanism of PKA-dependent and lipid-raft independent stimulation of Connexin43 expression by oxytoxin in mouse embryonic stem cells. Molecular Endocrinology 26 1144-1157. (doi:10.1210/me.2011-1343)

Received 17 December 2014

First decision 2 February 2015

Revised manuscript received 10 March 2015

Accepted 19 March 2015 